\title{
Research on Educational Architecture in Huainan Salt District of Jiangsu in Qing Dynasty
}

\author{
Xiaoli Zhang ${ }^{*}$, Kui Zhao \\ School of Architecture and Urban Planning, Huazhong University of Science and Technology, Wuhan, China \\ Email address: \\ 376919173@qq.com (Xiaoli Zhang),2417626840@qq.com (Kui Zhao) \\ ${ }^{*}$ Corresponding author
}

To cite this article:

Xiaoli Zhang, Kui Zhao. Research on Educational Architecture in Huainan Salt District of Jiangsu in Qing Dynasty. International Journal of Architecture, Arts and Applications. Vol. 6, No. 4, 2020, pp. 75-82. doi: 10.11648/j.ijaaa.20200604.12

Received: October 29, 2020; Accepted: December 4, 2020; Published: December 16, 2020

\begin{abstract}
The Qing Dynasty was the most prosperous period of Huainan's salt industry, and it was also the time when the educational buildings in the salt district achieved more development. Not only has the number of educational architectures increased, but the proportion of higher education buildings has also gradually increased. At present, the academic circles have made more in-depth research on ancient educational architecture, with many research achievements, the study on educational buildings in the Huainan Salt Region in the Qing Dynasties has not been fully developed. Only a few scholars have mentioned it slightly when studying salt towns. And it is limited to a simple introduction. As for the development, location, layout, and form of educational buildings in the Huainan Salt District, the in-depth content has not been involved. However, educational architectures are not only the carrier of cultural construction and development in the Huainan Salt District in the Qing Dynasties, but also one of the important factors affecting the development of salt settlements. Research on educational buildings in the salt districts is the starting point for a comprehensive study of the ancient sea salt settlement system, which has significant research value. This paper uses the interpretation method of historical documents to analyze the literature of the Qing Dynasty, such as "Chronicle of the Lianghuai sea salt industry" and "Chronicle of the Local". Use the time development as the vertical axis, making vertical comparisons, and studying the development and evolution of educational buildings in salt-producing towns, use the geographical scope as the horizontal axis, conducting a horizontal comparison, and studying the location and layout of educational architectures. On this basis, the relationship between the development of educational buildings and the evolution of the spatial form of salt-producing towns has been established, to fill the gaps in academic research on the educational architecture in the Huainan Salt District. At the same time, it also lays the foundation for the subsequent research on the sea salt settlement system.
\end{abstract}

Keywords: Salt-producing Towns, Educational Buildings, Site Selection and Layout, Huainan Salt District

\section{Introduction}

The Huainan Salt Industry Settlement is located on the eastern coast of Jiangsu Province and was developed from the salt industry administrative settlement of the Ming Dynasty. The salt settlements and agricultural settlements are separated by Chuanchang River and are distributed over a north-south belt along Chuanchang River. [1] Compared with the agricultural settlements, the development of educational buildings in the salt settlements is a little later, and the development speed is relatively slow. During the Jiajing period of the Ming Dynasty, the economy and policies of Huainan Salt District changed, the settlements were transformed from production villages to comprehensive towns, [2] the social structure changed, educational space entered, and the construction of community schools and academies began. In the Qing Dynasty, the salt industry settlements have begun to take shape, the economy has achieved greater development and transformation, and the demand for education has increased. [3] The Huainan Salt District occupies the convenient transportation of the Huai River, the Yangtze River, and the Canal. It is easy for intellectuals to enter the district. Besides, the salt merchants in the Qing Dynasty settled in the salt district, which made the salt industry settlement educational building space obtains greater development. The current academic research 
on education in Huainan Salt District mainly focuses on the analysis of historical motivations and related influencing factors. As for the educational building itself, it is only mentioned in the study of towns, but not in-depth. Based on the analysis of historical documents, this paper studies the types, location, and layout of educational buildings in the Huainan Salt Industry Settlement, and on this basis, studies the impact of educational building development on the spatial form of the salt industry settlements. Hope to provide a reference for the study of educational buildings in the Huainan salt settlement.

\section{Overview of the Development of Educational Architecture in the Salt-producing Towns in Huainan}

\subsection{Reasons for the Development of Educational Buildings}

The need for cultural popularization is the basis for the rapid construction of educational buildings in the salt-producing town of Huainan. The demand for the popularization of culture in the Huainan Salt District in the Qing Dynasty benefited from the salt industry policy implemented at that time. Since the failure of the kaizhong method in the Ming Dynasty, the government reformed the salt administration. The Qing government has followed this policy, which allowed merchant capital to enter the salt industry production area and gradually penetrated the administrative management of the salt industry, which had a great influence on the development and taxation of the Huainan salt industry at that time. So the salt merchant class and the Qing government formed an antagonistic and interdependent relationship. [4] Regarding salt merchants, although the government had conflicts of interest with them, it had to rely on the wealth in the hands of salt merchants. To obtain their support, the Qing government opened a convenient channel for its descendants to enter the imperial examination and established a separate merchant household registration. Allow the descendants of foreign businessmen to take imperial examinations in the Huainan Salt District, and vigorously develop education, and set up community schools in the Huainan salt settlement. [5] In dealing with salt people, the government hopes to maintain social stability. The salt producers in the Huainan Salt District have rough personalities, which can easily lead to conflicts. To change this status quo, maintain social order, and stabilize the salt farm population, the government also needs to develop basic education to educate the people. This greatly promoted the development of educational buildings in the Huainan Salt District.

The change of family social status is the main factor for the development of educational architecture. The social structure of Huainan Salt-producing Town in the Qing Dynasty was mainly composed of salt merchants, managers, wealthy salt producers, and other related industrial populations. Among them, the demand and funding for education from salt merchants, managers, and wealthy salt producers have enabled education buildings to achieve sustained and stable development. Merchants' supports for educational buildings are primarily for the long-term development of the family. Although merchants are extremely wealthy, their social status is generally low due to the influence of long-term culture. In order to change the status quo of the family and for the long-term development of future generations, they value cultural education very much. [6] The second is to show their financial strength and status. By hiring famous teachers, building school buildings, and funding many students to help them complete their studies, salt merchants show their wealth to society. With their support, educational buildings have been continuously developed and gradually have an important impact on the salt-producing town. [7]

\subsection{The Development and Evolution of Educational Architecture}

The number of educational buildings in salt-producing towns in the Qing Dynasty gradually increased. The educational buildings in the Huainan Salt District in the early Qing Dynasty were the same as those in the late Ming Dynasty, with a smaller number. [8] Among the 25 saltworks in the Taizhou, Tongzhou, and Huai'an branches, except for the ten saltworks in the Taizhou branch, which had community schools. [9] Only a few well-developed saltworks in Tongzhou and Huai'an had educational buildings. This situation was directly related to the economic, scale, and social structure of the Huainan salt saltworks at that time. Although there are 25 salt saltworks in Huainan, the development is not uniform. Only the ten salt saltworks of the Taizhou branch have a large production of salt and good quality. Moreover, the waterway is smooth, the distance is short, and the transportation cost is low. It has become the ten saltworks that the government attaches the most importance to, so the educational building was completed first. In the middle of the Qing Dynasty, both the output and the population of the Huainan Salt District increased significantly. [10] The overall economy of the salt district has achieved greater development. The 25 salt saltworks have been transformed into towns of a certain scale, and the social structure has changed from the original production population. Mostly it turned to a non-productive population, and the settlements themselves began to have a continuous demand for educational buildings. Therefore, after the second large-scale educational building construction activity in the Huainan Salt District in the 14th year of Kangxi, until the end of the Qing Dynasty, the development of educational buildings. There are twists and turns, but the total number is gradually increasing. As shown in Table 1, during the Kangxi period of the early Qing Dynasty, there were 12 educational buildings in Huainan Salt District, and there were 25 buildings in the late Qing Dynasty. 
Table 1. The number of educational buildings in Huainan Salt District in the Qing Dynasty.

\begin{tabular}{llll}
\hline Time & Number of educational buildings & Number of salt settlements & $\begin{array}{l}\text { Number of educational buildings /Number of } \\
\text { salt settlements (\%) }\end{array}$ \\
\hline Kangxi period & 12 & 25 & 0.40 \\
Yongzheng period & 15 & 25 & 0.52 \\
Qianlong period & 17 & 20 & 0.65 \\
Guangxu period & 25 & 20 & 0.90 \\
\hline
\end{tabular}

Explanation: The above data is based on the "Chronicle of ten saltworks in Central Huainan", "Chronicle of the Lianghuai sea salt industry (Ga, 1728)", "Chronicle of the Lianghuai sea salt industry (Wang, 1892)", "Chronicle of the Lianghuai sea salt industry (Wang, 1748)", "Chronicle of the Lianghuai sea salt industry (Xie, 1694)" collected and obtained.

In the Qing Dynasty, the ratio of the number of higher education and basic education buildings in the Huainan Salt District gradually increased. Due to the changes in the social structure of the salt-producing towns in the Qing Dynasty, the purpose of developing education also changed drastically. The salt-producing towns in the early Qing Dynasty were dominated by production personnel. The government developed education mainly to educate the people, so basic education buildings were the majority. Although higher education had developed at that time, the number of it was small and the proportion was low. In the middle and late Qing Dynasty, the salt-producing towns were dominated by merchants and managers, especially the wealthy Huainan salt merchants and newly developed wealthy salt producers. They hoped that their descendants could enter official careers through the imperial examination, so they were no longer satisfied with basic education, the demand for higher education increased greatly. It is this factor that caused the rapid development of higher education buildings in the middle and late Qing Dynasty, and the number increased. [11] Although it was not popularized in every salt-producing town, its ratio to the number of basic education buildings was far greater than in the early Qing Dynasty. As shown in Table 2, the ratio of higher education to basic education was only 0.2 in the early Qing Dynasty, but by the end of the Qing, This ratio has reached 0.38 , and more importantly, the increase in this ratio has also had an important impact on the space of salt-producing towns.

Table 2. Comparison of the ratio of the number of higher education buildings to the number of basic education buildings in Huainan Salt District in the Qing Dynasty.

\begin{tabular}{llll}
\hline Time & $\begin{array}{l}\text { the number of higher } \\
\text { education buildings }\end{array}$ & $\begin{array}{l}\text { the number of basic } \\
\text { education buildings }\end{array}$ & $\begin{array}{l}\text { the number of higher education buildings / the } \\
\text { number of basic education buildings (\%) }\end{array}$ \\
\hline Kangxi period & 2 & 10 & 0.2 \\
Yongzheng period & 2 & 13 & 0.16 \\
Qianlong period & 4 & 13 & 0.30 \\
Guangxu period & 7 & 18 & 0.38 \\
\hline
\end{tabular}

Explanation: This table only sorts out the number of academies, but the development of educational buildings in the Huainan Salt District to the Qing Dynasty has added two types of private schools and public welfare schools. However, due to incomplete relevant information, this paper will not focus on research.

\section{Classification of Educational Buildings in the Salt-producing Towns in Huainan}

From the above analysis, it can be seen that due to different educational requirements, the educational buildings in the salt-producing town of Huainan in the Qing Dynasty were mainly divided into two types, namely, community schools for basic education and academy buildings for higher education.

\subsection{Community School in the Salt-producing Town}

Community schools in the salt-producing town of Huainan mainly conduct basic education. They were established under the leadership of the government, with enlightenment as their main goal, and children under the age of 15 as the main educational objects. The nature of its use, and the objects of its creation and use determined that the composition of the space was mainly practical, and the scale did not need to be large. This paper analyzes and sorts out the records of community schools in the "Chronicle of the Lianghuai sea salt industry", "Chronicle of the Local" and other documents in the Qing Dynasty. It is found that the architectural space is mainly composed of teaching space, living space, and rest space (Figure 1). Teaching space is its core, while other spaces are slightly increased or decreased depending on the scale of the building.

\subsection{Academy in the Salt-producing Town}

The academy buildings mainly carried out higher education in the salt-producing towns of Huainan in the Qing Dynasty, intending to cultivate imperial examination talents. Therefore, the number of academies buildings was less than that of community schools. Although the academy had a certain scale in the early Qing Dynasty, it only flourished in the middle and late Qing Dynasty. According to documentary records, there were Xixi Academy and Taidong Academy in Dongtai, and Nansha Academy in Bingcha, in the early Qing Dynasty. [12] In the middle and late Qing Dynasty, in addition to the above three academies, Academy in Fengli Town, Wenzheng Academy in Shigang Town, Academy in Lusi Town, Jingjin Academy in Yuxi Town, Dongjian 
Academy in Yudong Town, Shouzheng Academy in Jiaoxie Town, Zhengxin Academy in Caoyan Town, Chongwen Academy in Wuyou Town, and Zilang Academy in Tongzhou were added. [13] Although the number is still less than community school, its development process is more stable than that of the community school. After its completion, although there have been changes, it has rarely been abolished. Until the end of the Qing Dynasty, many academies in the salt settlement of Huainan were still in use, and new academies appeared constantly.

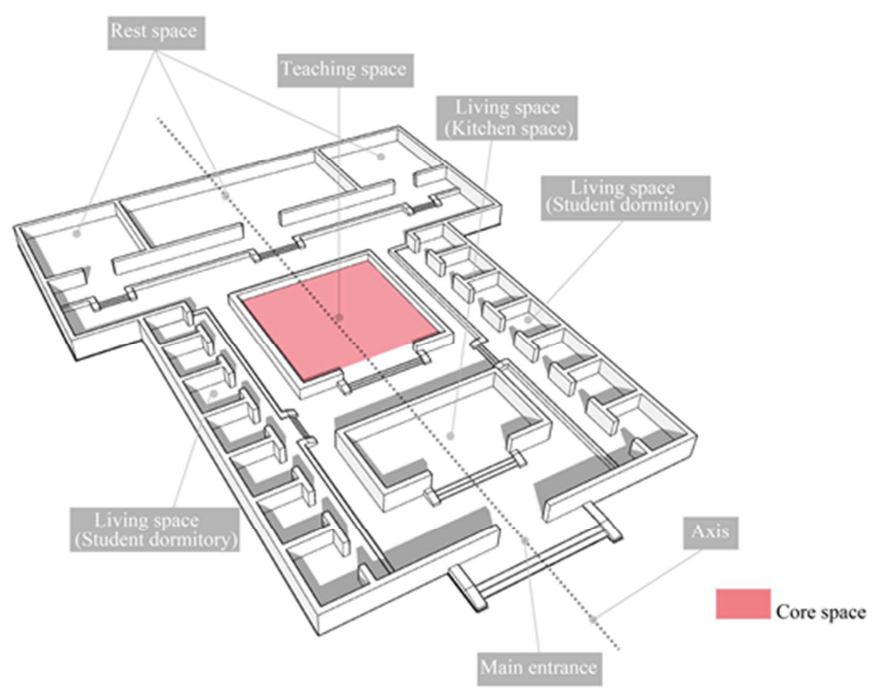

Figure 1. Schematic diagram of the spatial composition of community schools in the Huainan Salt District in the Qing Dynasty.

\section{Site Selection of Educational Buildings in the Salt Production Town of Huainan}

Different types of educational buildings have different locations. Due to the special status of the Huainan salt industry in the Qing Dynasty economy, the educational buildings in the salt-producing towns not only have educational functions, but also certain administrative functions. Therefore, the different needs make the location of community schools and colleges different.

\subsection{Located in the Center of the Salt-producing Town}

Community school buildings were mostly located in the center of the salt-producing town. From the previous analysis, knowing that the community school conducts primary education, and one of the main purposes of its development was to educate the people, which was also one of the local administrative functions. Therefore, the majority of community school buildings were located in the center of the salt-producing town. Besides, the site selection was also affected by administrative management factors, combined with the combined effects of the ease of use, construction funds, culture, and other comprehensive factors, so the site selection was either around the highest administrative space in the salt-producing town or the main settlement. One side of the street. As shown in Table 3, the community schools in Jiaoxie Town and Xiaohai Town were close to administrative space, while community schools in Fu'an Town and Liangduo Town were located on the side of the main street.
Table 3. Analysis diagram of different locations for community schools in Huainan Salt Industry Settlement.

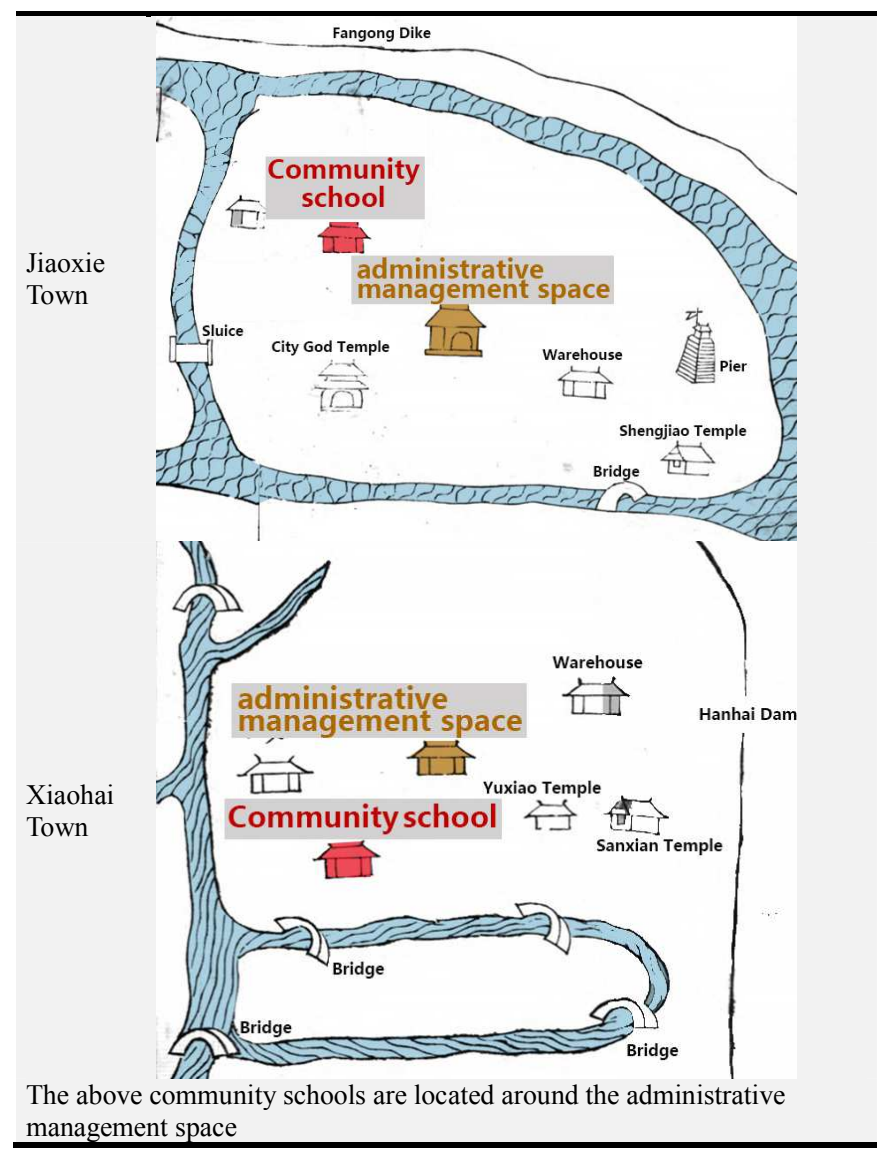




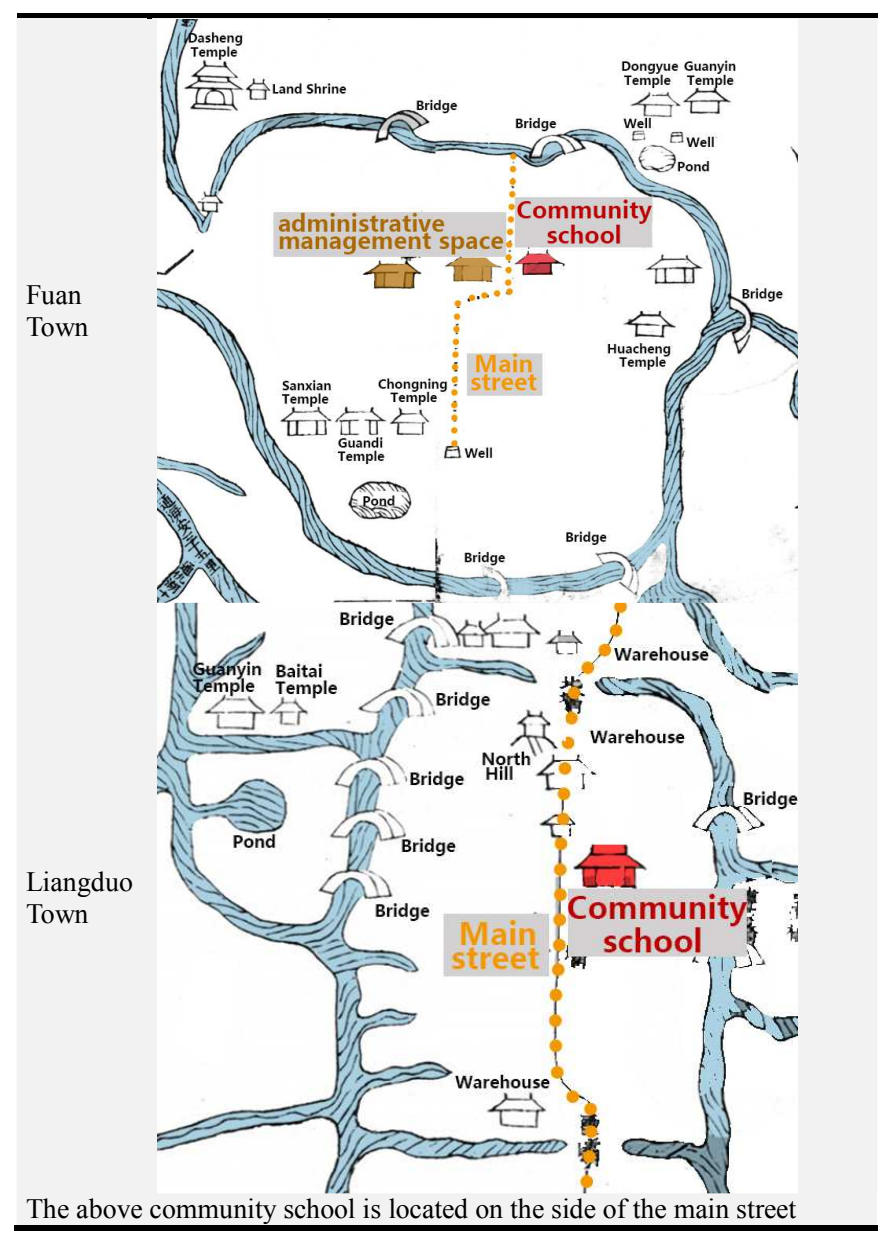

\subsection{Located on the Edge of the Salt-producing Town}

The location of the academy building is mainly on the inner edge of the salt-producing town. Although Huai salt tax accounted for half of the country's overall salt tax in the Qing Dynasty, and salt merchants were also very rich, the profits generated by Huai salt were mainly concentrated in Yangzhou and its surrounding cities. The salt field is located along the coast, with frequent natural disasters and a harsh environment, and it is the basic level of Huainan salt industry management. Therefore, neither the government nor the salt merchants have strong financial resources, and those who enter the academy are mostly poor. Under this circumstance, the site selection of academies in the salt-producing Town does not have high requirements for the scenery, which is not the same as the selection of sites for academies in urban settlements such as Yangzhou, Huai'an, and Taizhou in beautiful suburbs. [14] Choosing a site in a beautiful suburban area to build an academy requires a lot of capital investment. However, in the salt-producing town of Huainan, the salt merchants and the government have limited financial resources and it is difficult to make this choice. Besides the inconvenient transportation and high travel costs on the outskirts of the town make it even worse for the poor salt farm students. Therefore, the academy buildings in salt-producing towns are mostly located on the inner edge of the town, or rebuilt on the old site, or make renovations on existing buildings such as temples and palaces.
In this way, there is a certain distance from the noisy core block, which is conducive to obtaining a quiet learning environment, which can meet the distance requirements of students and can also ensure that the college is protected from floods and can be used for a long time. [15] For example, the Xixi Academy in Dongtai, during the Qianlong period, borrowed the West Building of the Tzu Chi Temple in Yanzhen Town as a teaching space. Later, the merchants paid for the houses, tables, and chairs to build the academy; Nansha Academy of Bingcha town is located on the west side of Fangong Dyke.

\section{Layout of Educational Buildings in the Salt-producing Settlements in Huainan}

According to the analysis in the third part of the previous article, the main space of the educational building in the salt-producing town of Huainan in the Qing Dynasty consists of four parts: entrance space, teaching space, living space, and rest space. According to the topography and building scale of each town, the central axis symmetry and free layout of these two different plane forms.

\subsection{Central Axis Symmetry}

The central axis symmetry is the main spatial form of the educational buildings in the salt-producing town of Huainan. The educational buildings in salt-producing Towns are mostly government-led or participated in the construction, so the architectural layout is deeply influenced by official buildings. Because educational buildings are mostly rebuilt on old sites or rebuilt on existing buildings, they are affected by traditional culture and residential buildings, so central axis symmetry is the main layout of educational buildings.

Under the overall layout of central axis symmetry, educational buildings are small in scale due to factors such as the financial resources of salt-producing towns, the number of users, and the administrative level. The layout is dominated by two or three courtyards and is only uniaxial symmetric. The entrance space, teaching space, and rest space are located on the central axis, with student dormitories on both sides, surrounded by walls, which is the general layout of educational buildings in salt-producing towns. Compared with urban settlements such as Yangzhou and Huai'an, the composition of educational space in the Yan District is slightly thinner. For example, in Yangzhou Anding Academy, according to Qianlong's "Chronicle of the Lianghuai sea salt industry", the academy presents a three-axis parallel layout, and the space composition is also diverse. In addition to teaching space and student dormitories, there are also book collection spaces and belief spaces. Space is partitioned by multi-axis paralleling, forming three large areas, namely the faith area, the teaching area, and the living area (Figure 2). Comparing the Xixi Academy in the salt-producing town, it can be found that Xixi Academy is only uniaxially symmetrical, with only two parts, teaching space and living space, and the scale is relatively small 
(Figure 3). Xixi Academy is a well-developed and larger academy in the Huainan Salt District. Comparing it with the Anding Academy in Yangzhou, it can highlight the difference between the educational buildings in the salt-producing towns and the urban educational buildings. The comparison can also reflect the characteristics of the educational building layout in the Huainan Salt District.

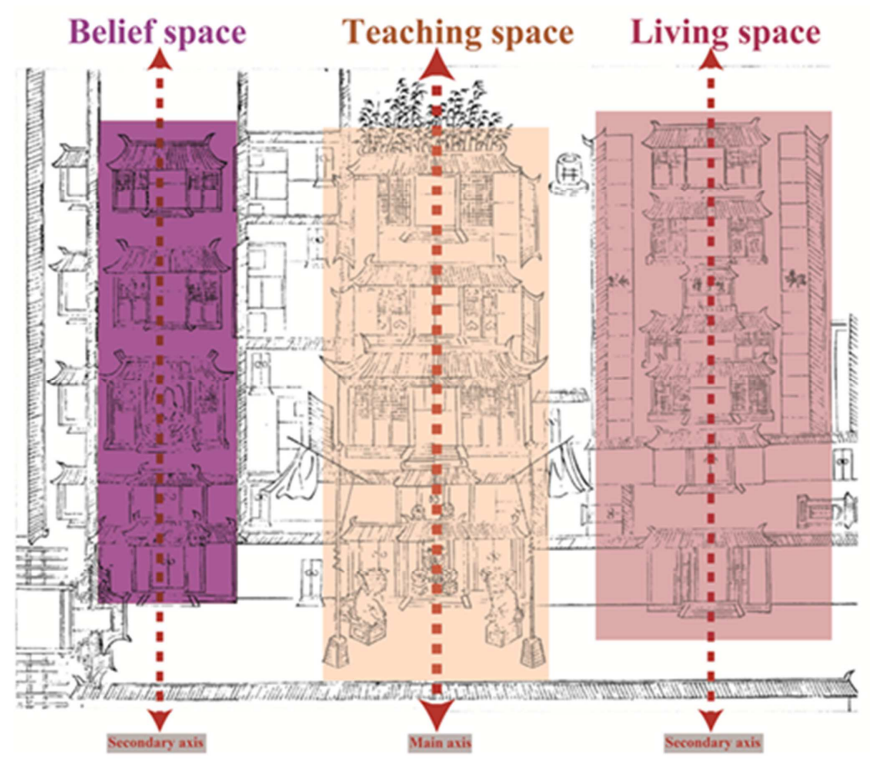

Figure 2. The Layout of Yangzhou Anding Academy in Qing Dynasty.

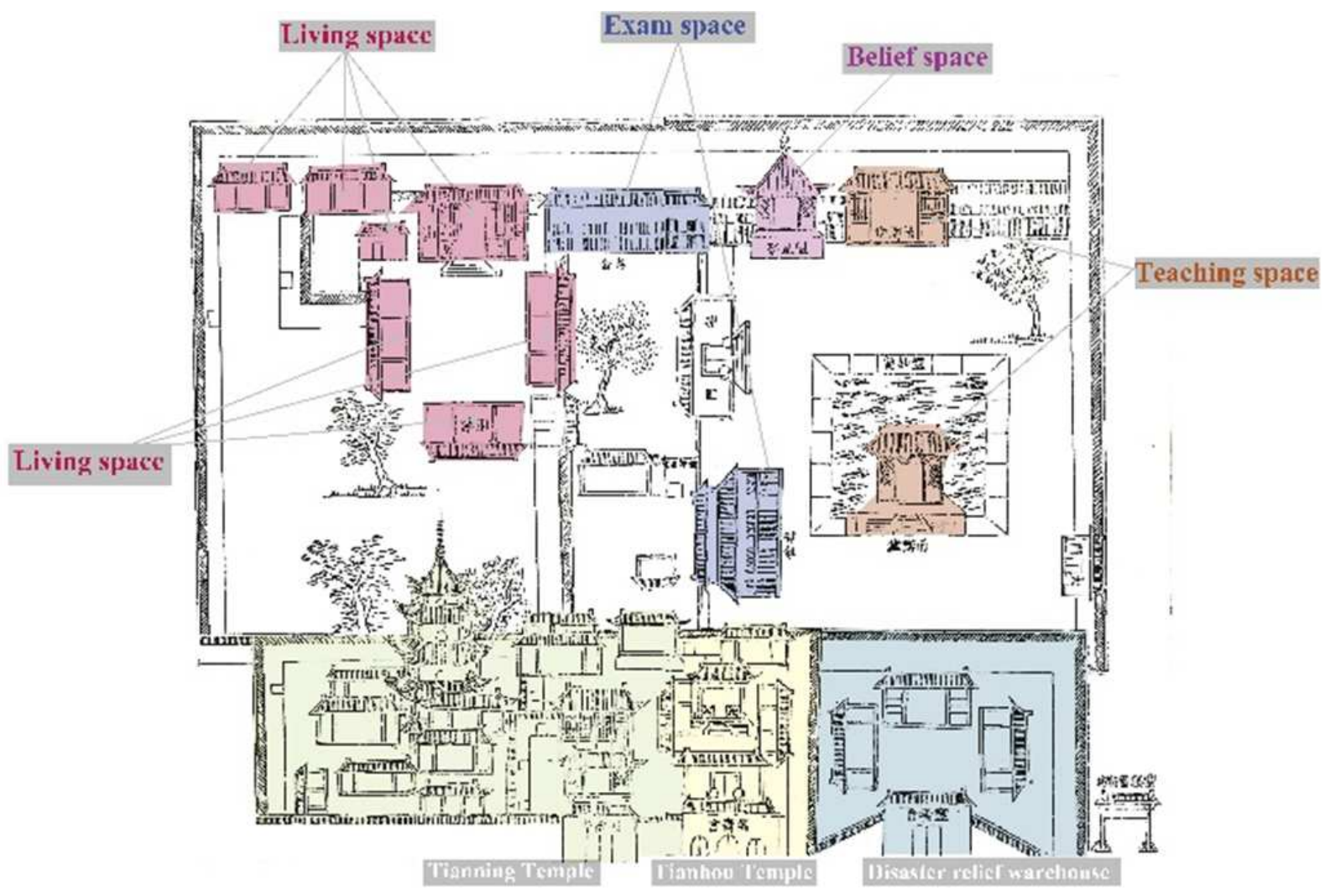

Figure 3. The Layout of Xixi Academy, a salt settlement in the Qing Dynasty.

\subsection{Free Layout}

The free layout is also one of the methods adopted by the educational buildings in Yanzhen Town. The Chinese culture has long been integrated with everyone, especially the ancient literati. The longing for nature and the need for aesthetics in the culture make them create as much artistic conception as possible under the circumstances of natural and economic conditions. In particular, the Huainan Salt District is close to Jiangnan and Yangzhou and is also the area where 
many intellectuals in the Qing Dynasty gathered. Therefore, the layout of a small number of newly built academies, while meeting functional requirements, also tended to be garden layouts. A free layout form has emerged. However, such academies are relatively rare in the settlements of Huainanchang Town. Only in the locations of the branches with better economic development, can such academies with such layouts be built. Among them, the Zilang Academy of Tongzhou Branch The academy is the most typical. Zilang Academy is separated from Yanyicang, Wanshou Palace, and Tianning Temple by a wall. The academy consists of teaching space, living space, and examination space. The teaching space is different from other salt-producing academies, which are divided into two parts. The front part is an open outdoor space, facing the entrance, and the rear teaching space is indoors. The inside of the academy separates the teaching space from the examination space through the door and uses the gatekeeper to separate the examination space from the living space (Figure 4).

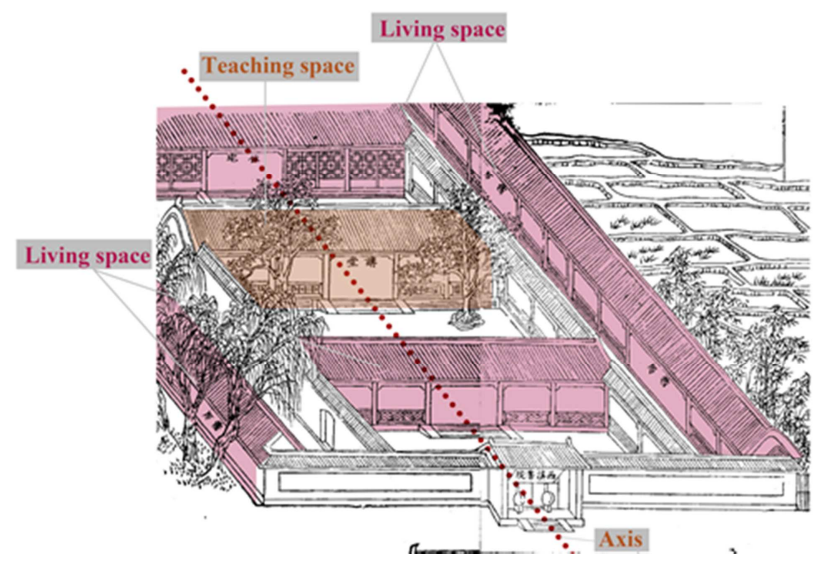

Figure 4. Schematic diagram of the free layout of Tongzhou Zilang Academy in Qing Dynasty.

\section{The Influence of Huainan Educational Architecture on the Spatial Form of Salt-producing Settlement}

The development of educational buildings in the Qing Dynasty had a significant impact on the spatial form of salt-producing towns. The economy, administration, and population of them play a decisive role in the development of educational buildings. However, after the completion, the educational buildings have become a central part of the space of the salt-producing town, which will make dominant and recessive effects on the development and evolution of the spatial form of the salt-producing town. The dominant influence is more direct, formed by the educational building itself. After the educational building is completed and put into use, the route of student activities will not only affect the distribution of residential and commercial areas in the town but also may affect the overall road network planning. Invisible effects generally take a long time to produce, but their influences are often far-reaching. The hidden effect of educational architecture is formed by cultural communication, which is a long-term process. The rise of educational buildings in salt districts not only has a certain educational effect on the people but also establishes a channel for the people in salt-producing towns to enter official careers and accelerate the change of the social structure. Due to the changes in the social structure of the salt-producing town, the participation of merchants, and the overall improvement of the cultural level of residents, education has gradually received attention. Building spaces related to education and culture have gradually increased in the settlements, such as Wenchang Pavilion and Confucian Temple. These buildings are often the landmarks, and they dominate the overall form of salt-producing towns. Therefore, based on the above analysis of the explicit and implicit effects, it can be seen that not only the various factors in the salt-producing town will have an impact on the educational buildings, but the development of educational buildings will also have a certain effect on the space of the salt-producing town.

\section{Conclusion}

In the Qing Dynasty, not only the overall number of educational buildings in the Huainan Salt District increased, but the proportion of higher education buildings also gradually increased. The increase in the number of educational architectures reflects the increase in the cultural penetration rate of the Huainan Salt District in the Qing Dynasty, and it also reflects the increase in the level of economic development in the salt district from the side. The increase in the proportion of higher education was the result of the changes in the social and economic structure of the salt district in the Qing Dynasty. When the salt district was dominated by production personnel, there was less demand for higher education and the town functions were simple, only production and management. When the non-productive population and the wealthy population in the salt area increased, the demand for higher education expanded. This change promoted the gradual enrichment of the educational space and the spiritual space in the salt-producing towns.

Educational buildings are located in the central or peripheral areas of Salt-producing Town, mostly presented in the form of axis symmetry or free layout, and the overall scale is relatively small. Due to the influence of various factors such as geographical location, economic development, administrative management, natural disasters, etc., the internal space of the salt-producing town has become the best site for educational architecture, and the final location of the architecture in the center or the edge of the salt-producing town depends on different types of Attributes of educational architectures. At the same time, because educational architecture is the dissemination point of Chinese culture, it is the type of architecture that has been most profoundly influenced by Chinese culture. The architectural layout fully embodies the two different architectural ideas of "ritual system" and "harmony of nature and man", so there are two 
kinds of architectural layout forms.

Although the number of educational buildings in the Huainan Salt District is relatively small today, the impact of educational space on the overall space of salt-producing towns is still there. The paper conducts comprehensive research on the educational buildings of Huainan Salt-producing Town from the micro and meso perspectives, establishing the relationship between the development of single buildings and the evolution of the overall morphology of the settlement, to fill the current academic vacancy in the research of educational buildings in Huainan Salt-producing Town.

\section{Acknowledgements}

This article is funded by the National Natural Science Foundation of China, the fund number is 50978111, and the article is also a preliminary result of the 2017 National Publishing Fund Project "Ancient Chinese Salt Archaeology and Salt Civilization". We wish to thank three anonymous reviewers for their helpful comments and suggestions on the original manuscript.

\section{References}

[1] Liao Yu. (2019). Research on the Settlement System of Huainan Salt Field in Ming and Qing Dynasty [D]. Southeast University, (03) 39-42.

[2] Li Lan, Li Xinjian. (2017). Evolvement of Saltern Authority Settlements in Huai Region of Jiangsu Coastal Area. Modern Urban Research, 000 (012): 96-105.

[3] Zhao Yi. (1986). Changes in the production relations of the salt industry in the Ming Dynasty. Journal of Northeast Normal University (Philosophy), (04): 49-55.

[4] Bao J, Gao S. (2016). Traditional coastal management practices and land-use changes during the 16-20th centuries, Jiangsu Province, China. Ocean \& Coastal Management, 124: 10-21. doi: 10.1016/j.ocecoaman.2016.02.006.

[5] Cao Yongxian. (2002). The Migration and Merchant
Registration of Salt Merchants in Huizhou in the Ming Dynasty. Studies in Chinese Social and Economic History, 000 (001): 32-38.

[6] Lu Yuqin, Zhang Yi. (2018). The Value Orientation of the Confucian Scholars of the Salt People and the Rise and Fall of the Kitchen Household Clan in Huainan Salt Field during the Ming and Qing Dynasties: An Interpretation of "Qiu Family Genealogy" by Wenjintang in Jinshachang. Journal of Yangzhou University (Humanities) Social Science Edition), 22 (05): 113-120.

[7] Si Zhimin. (2019). Cultural Consciousness and Social Responsibility — A Study on the Contribution of Yangzhou Salt Merchants to the Educational Development of Academy. Journal of Guizhou Normal University, 035 (011): 21-30.

[8] Chang Jianhua. (2019). Re-discussion on the social economy and life of Jiangsu in the middle of the Qing Dynasty-focusing on the investigation of occupation and livelihood. Academia, 248 (01): 129-141.

[9] Shi Qizhe. (2010). Chronicle of ten saltworks in Central Huainan, Beijing: Fangzhi Publishing House, (02): 106-108.

[10] Xia Xianlong. (2017). Research on the towns of Lianghuai Saltworks in Qing Dynasty. Liaoning: Liaoning Normal University, (04): 46-47.

[11] Zhang Xiaoli. (2018). Research on the settlements and buildings along the Huaiyan transportation line: based on the salt map of the four provinces in the Qing Dynasty. Huazhong University of Science and Technology, (04) 47-52.

[12] Wang Zhaozhang. (1673). Ten Chronicles of Huainan Middle School. National Library, (02): 91-95.

[13] Yu Hao. (1748). A rare series of economic historical materials of the Ming and Qing Dynasties (first series). National Library Press, (04): 584-598.

[14] Qiao Aiyi. (2013). Site selection and types of Jiangsu academy buildings. Nanjing: Nanjing University of Technology, (03): 20-40.

[15] Zhang Chongwang. (2004). Research on Interactive Relation between Natural Disasters, Society and Economy in Jianghuai Region in Ming and Qing Dynasties. Xiamen University, (02) 87-97. 